\section{The relationship between skin phototype, gender, and stress level with the incidence of acne vulgaris among adolescents in Surakarta}

\author{
Ardian Hendra Rezi Pamungkas, ${ }^{1}$ \\ Flora Ramona Sigit Prakoeswa ${ }^{2}$ \\ ${ }^{1}$ Faculty of Medicine; ${ }^{2}$ Department of \\ Dermatology and Venereology, \\ Muhammadiyah University of \\ Surakarta, Indonesia
}

\begin{abstract}
Abstrac
Acne vulgaris (AV) is formed by inflammation of the sebaceous follicles with the prevalence hits its peak during the adolescence. It can be occurred by factors including skin phototype, gender, and stress. However, there is still limited study discussing on skin phototype and the AV prevalence especially in Asian descents. Besides, it is currently unclear which factor is most influential in affecting AV. The aim of this study was to evaluate the relationship between skin phototype, gender, and stress level with the incidence of AV among adolescents. This was a cross-sectional study with 102 adolescents aged 14-18 years old as respondents. Data were collected by doctor's examination (intra-rater, kappa $=0.805$ ) with 3 questionnaires consists of Perceived Stress Scale (PSS), Minessota Multiphasic Personality Index (MMPI-2) lie-scale, and Fitzpatrick Skin Type (FST). Chi-square test showed the significant $p$ value $(p<0.05)$ in all variables. Regression logistic showed gender had the greatest Odds Ratio $(\mathrm{OR}=38.610)$ followed by skin phototype $(\mathrm{OR}=8.226)$ and the stress level $(\mathrm{OR}=5.612)$. There was significant relationship between skin phototype, gender, and stress level with the incidence of AV among adolescents in Surakarta.
\end{abstract}

\section{Introduction}

$\mathrm{AV}$ is a skin disease formed by chronic inflammation of the sebaceous follicles which can heals by itself. Its lesions may vary for each patient like comedones, papules, pustules, nodules, and often scars. Its predilection includes face, neck, ears, upper back, chest, and shoulders. ${ }^{2}$ The prevalence of this disease is mostly experienced by adolescents with more than $85 \%$ of them affected. ${ }^{3}$ Generally before the age of $25 \mathrm{AV}$ will be healed even though about $12 \%$ of women and $3 \%$ of men will still have the disease until the age of 44 years old. ${ }^{1}$

The incidence of $\mathrm{AV}$ is most prevalent in the 15-18 aged range, with prevalence of both boys and girls almost equal. ${ }^{1}$ Research conducted by Yiwei et al. ${ }^{4}$ to measure the prevalence of AV in Chinese population by involving 947 adolescents aged 15-19 showed higher prevalence in boys $(41.3 \%)$ than in girls (33.7\%). This result was different from Noorbala et al. ${ }^{5}$ who conducted a similar study in Iran involving 419 adolescents aged between 15-18 years. The result showed that adolescent girls had a higher prevalence of AV (90\%) compared with boys $(81.4 \%)$.

$\mathrm{AV}$ is also affected by skin type characteristics, the Fitzpatrick Skin Type (FST). The grouping is based on whether the skin will get sunburn or pigmented (tanning) after exposure to sun. ${ }^{6}$ Perkins et al. ${ }^{7}$ indicate that African-American (FST V-VI) women had the highest tendency to suffer AV (37\%) when compared with other ethnic groups such as Caucasian (FST I-III), Asian (FST II- IV), and continental Indian (FST III-V).

$\mathrm{AV}$ affects the psychosocial aspect of patients. Feelings of anxiety, depression, low self-esteem, and embarrassment are often felt by people suffering AV especially adolescents. ${ }^{8}$ Beside, AV can also be triggered by stressful conditions. Research by Hadi and Awadh on 98 pharmacy students of International Islamic University Malaysia in cross-sectional design showed a positive relationship between stress level with the incidence of AV although statistically not significant. ${ }^{9}$

AV is affected by other risk factors such as hormones, age, sex, stress and cosmetics. ${ }^{10}$ The hormone which plays a role in increasing sebum production is androgen. The androgen binds to sebocyte, then affects the proliferation and differentiation of sebocyte. Dyhidrotestosterone (DHT), a potent androgen hormone, may also plays an important role in stimulating the proliferation of follicular keratinocytes. This can be seen from the average serum androgen level in AV patients is higher when compared with normal people. ${ }^{3}$ Most of androgen in the body circulates in the form of testosterone. ${ }^{11}$

In this study, authors wanted to evaluate the relationship of skin phototype, gender, and stress level with the AV incidence among adolescents in Surakarta.
Correspondence: Flora Ramona Sigit Prakoeswa, Faculty of Medicine, Muhammadiyah University of Surakarta, Kampus IV UMS, Jl. Ahmad Yani, Gonilan, Kartasura, Gonilan, Kartasura, Sukoharjo, Central Java 57169, Indonesia.

Phone: 6287835557633.

E-mail: frsp291@ums.ac.id

Key words: acne vulgaris, skin phototype, gender, stress level.

Acknowledgements: The authors thank high school students in Surakarta for being respondents in this study.

Contributions: AHRP, collected the data, performed statistical analysis, wrote the manuscript in consultation with author 2, final approval of the version to be published; FRSP, conceived and designed the anlysis, developed the theoretical framework, critical feedback and revision of the manuscript, final approval of the version to be published.

Conflict of interest: the authors declare no potential conflict of interest.

Funding: This study was funded by authors.

Conference presentation: This study has been presented as poster at the $23^{\text {rd }}$ Regional Conference of Dermatology (AsianAustralasian) incorporating with the 16th Annual Scientific Meeting of the Indonesian Society of Dermatology and Venereology in Surabaya-Indonesia, 8-11 August 2018.

Received for publication: 1 February 2019 Accepted for publication: 11 February 2019

This work is licensed under a Creative Commons Attribution-NonCommercial 4.0 International License (CC BY-NC 4.0).

(C) Copyright A.H.R.Pamungkas and F.R.S. Prakoeswa 2019

Licensee PAGEPress, Italy

Dermatology Reports 2019; 11(s1):8035

doi:10.4081/dr.2019.8035

\section{Materials and Methods}

\section{Respondents and data collection}

This study used analytic observational method with cross sectional design. It was conducted at Public High School in Surakarta-Indonesia with 102 students aged 14-18 years old as respondents. They were consisting of 57 male and 45 female. Subjects were taken by purposive sampling method. Inform consent for data collection was obtained and the identities of all respondents were taken anonymously. Respondents in menstrual period, 
undergoing treatment for $\mathrm{AV}$, and suffered skin diseases on the face such as perioral dermatitis, rosacea, seborrheic dermatitis, and folliculitis were excluded from study. AV was diagnosed by doctor's examination (intra-rater, 0.805 kappa).

\section{Questionnaires}

This study used 3 questionnaires to collect data from respondents, the first was liescale MMPI-2 to measures the respondents honesty in answering other questionnaires. Lie-Scale consist of 15 sentences which contain attitudes and practices that are culturally laudable. Then PSS to measure and classify stress level of respondents in low, moderate or high perceived stress. It provides a potential tool for examining issues about the role of stress level in the etiology of disease. PSS consist of ten questions asking about respondent's feelings and thoughts during the last month with the answer scale from 0-4. Higher scale showed higher frequency of respondents feeling during the last month. Score total ranging from $0-13$ would be considered low stress, 14-26 considered moderate stress, and 2740 considered high perceived stress. ${ }^{12}$ The other one was self-assessment skin phototype from research by Magin et al. ${ }^{13}$ to assess the characteristic of respondents skin based on FST. The gender was identified from the identities database given by school. Data obtained from the doctor's examination and questionnaires then analyzed using chi-square and logistic regression test.

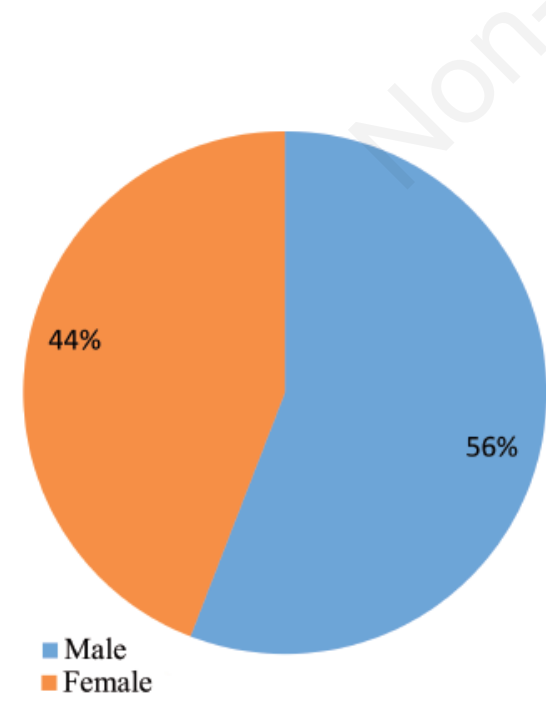

Figure 1. Sex distribution (Reference: primary data).

\section{Results}

Through the purposive sampling method, a total of 102 high school students in Surakarta include in this study. Data were taken by questionaires and examination by doctor. Figure 1 showed respondents sex distribution comprised of 57 boys and 45 girls.

The age ranged from 14-18 years old. Based on doctor examination (Intra-rater, 0.805 kappa) 25 (24.5\%) respondents rated having no AV. From Table 1 the overall prevalence of AV was $75.5 \%$ and it was more common among boys $(94.7 \%)$ than in girls $(51.1 \%)$.

Using PSS questionnaire as seen on Figure 2, 18 (18\%) respondents considered in low stress, $54(53 \%)$ in moderate stress, and $30(29 \%)$ in high perceived stress. AV seen most common in high perceived stress group $(92.9 \%)$ than in moderate stress $(83.3 \%)$ and low stress $(22.2 \%)$.

Skin phototype in this study was rated by self-assessment questionnaire after the explanation of sunburn and tanning from authors. $^{13}$ Figure 3 showed most of respondents choose type IV as their skin phototype $(49 \%)$, followed by type $\mathrm{V}$ (37\%), type III (12\%) and type II (2\%). There was 1 respondent choosing type I but excluded from the study because in menstrual period. AV happened most commonly in type $\mathrm{V}$ skin phototype as seen in Table 2 (94.8\%).

Based on chi-square tests there were siqnificant relationship between skin phototype $(95 \% \mathrm{CI} p=0.000)$, gender $(95 \%$ CI $\mathrm{p}=0.000)$, and stress level $(95 \% \mathrm{CI}$

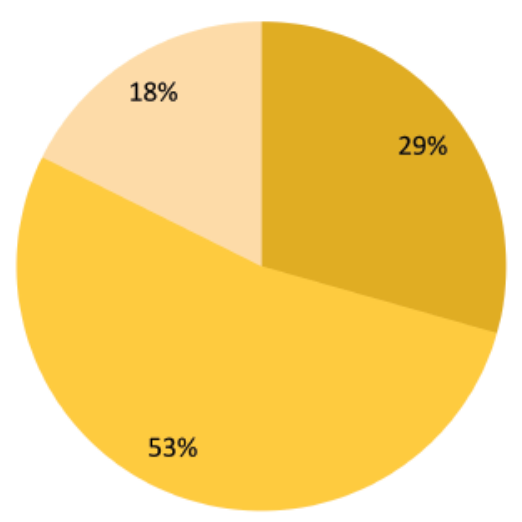

= High perceived stress

Moderate stress

Low stress

Figure 2. Stress level distribution. $\mathrm{p}=0.000)$ with the incidence of AV among adolescent students. Data then analyzed using logistic regression (Table 3) to evaluate the most influential factor impacting AV in adolescent students.

From Table 3 gender had the lowest significancy $(95 \% \mathrm{CI} p=0.000)$ with highest odds ratio $(\operatorname{Exp}(\mathrm{B})=38.610)$, meaning that boys had 38.61 times higher chances for

Table 1. AV prevalence based on gender.

\begin{tabular}{lccc} 
AV & \multicolumn{2}{c}{ Gender } & Percent \\
Diagnosing & Male & Female & \\
Positive & $54(94.7 \%)$ & $23(51.1 \%)$ & $75.5 \%$ \\
Negative & $3(5.3 \%)$ & $22(48.9 \%)$ & $24.5 \%$ \\
\hline Total & 57 & 45 & $100 \%$ \\
\hline
\end{tabular}

Reference: primary data.

Table 2. AV prevalence based on skin phototype.

\begin{tabular}{lccc} 
FST & \multicolumn{2}{c}{ AV diagnosing } & Total \\
& Positive & Negative & \\
Type II & $0(0 \%)$ & $2(100 \%)$ & $2(2 \%)$ \\
Type III & $2(16.7 \%)$ & $10(83.3 \%)$ & $12(11.8 \%)$ \\
Type IV & $11(22 \%)$ & $39(78 \%)$ & $50(49 \%)$ \\
Type V & $36(94.8 \%)$ & $2(5.2 \%)$ & $38(37.2 \%)$ \\
\hline
\end{tabular}

(Reference: Primary data).

Table 3. Regression logistic test.

\begin{tabular}{lcc} 
Factors & Significancy & Exp (B) \\
Skin phototype & 0.002 & 8.226 \\
Gender & 0.000 & 38.610 \\
\hline Stress level & 0.011 & 5.612
\end{tabular}

(Reference: primary data).

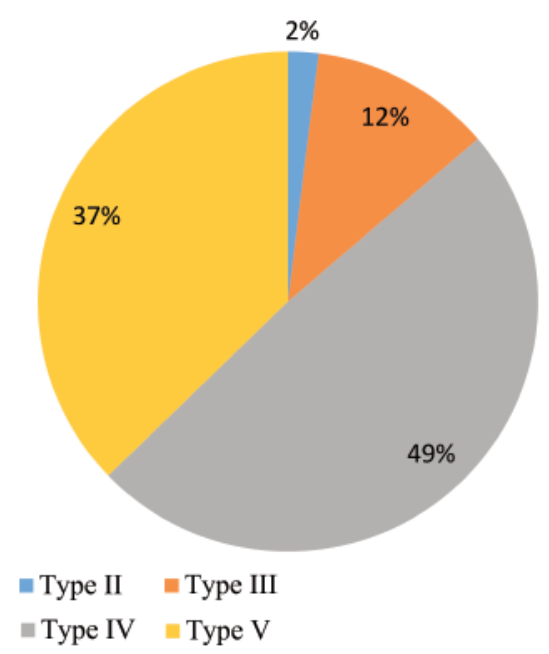

Figure 3. Skin phototype distribution (reference: primary data). 
getting AV than girls. Skin phototype (95\% CI $p=0.002)$ had odds ratio $(\operatorname{Exp}(B)=8.226)$ higher than stress level $(95 \%$ CI $\mathrm{p}=0.011$ $\operatorname{Exp}(B)=5.612)$. It means adolescent with high characteristic of skin phototype was more prone to $\mathrm{AV}$ than adolescent with high level of stress, but the most influential risk factor for suffering AV was being male.

\section{Discussion}

The aim of this study was to evaluate the relationship between skin phototype, gender, and stress level with the incidence of AV among adolescents. Factors measured were skin phototype, gender, and stress level. The prevalence of AV obtained in this study reached $75.5 \%$ out of 102 participating students. The high prevalence of AV in this study was similar according to Zaenglein et al. ${ }^{3}$ who stated that AV hits its peak during adolescent period.

The results of this study also similar with Yiwei et al. ${ }^{4}$ in terms of AV prevalence in boys and girls. They measured AV prevalence in Chinese population by involving 947 adolescents aged 15-19 years and found that AV prevalence in boys were higher $(41.3 \%)$ than in girls $(33.7 \%)$. In this study the prevalence of $\mathrm{AV}$ in male students $(94.7 \%)$ were higher than in female students $(51.1 \%)$. In both men and women, pituitary gland begins to activate gonadotropin in adolescent period. This phase is often called puberty, the period when the endocrine and gametogenic gonads develop into reproductive function. Age of puberty varies in each person, but generally in girl ranged between 8-13 years old, and in boys 9-14 years old. At this point, the secretion of androgen also increased dramatically. Its secretions are regulated by Adrenocorticotropic Hormone (ACTH) produced in pituitary gland. ACTH will further stimulates the adrenal cortex to produces Dehydroepiandrosterone (DHEA). ${ }^{11}$ In the pathogenesis of $\mathrm{AV}$, DHEA plays an important role in formation of Dihydrotestosterone (DHT), which then increases sebum production and stimulates follicle keratinization process. ${ }^{3}$ Boys have significant higher testosterone level than girls during puberty. ${ }^{11}$ Maybe this difference were the underlying caused why boys more risky getting AV than girls. Logistic regression analysis in this study also showed that being male was the most significant risk factor of getting $\mathrm{AV}$ compared with the skin phototype and level of stress.

We found that students with severe stress level tend to be prone getting AV than students with mild stress level. An earlier study in 98 college students of Malaysia International Islamic University also showed a positive relationship between stress level and the incidence of AV. ${ }^{9}$ Stress in a long period of time will triggers the activation of the endocrine system through Hypothalamic Pituitary Adrenal (HPA) axis. Corticotropin Releasing Hormone (CRH) will induce the pituitary gland to secrete ACTH, then after it reaches adrenal cortex the androgen is secreted. ${ }^{14}$ Androgen hormone will be converted to DHT which contributes in increasing sebum production and keratinizing of hair follicles. ${ }^{3}$

Skin phototype in this study showed a significant relationship with the incidence of AV in adolescent students $(p=0.002)$. Students with high skin phototype had $(\mathrm{OR}=8.226)$ greater risk of developing $\mathrm{AV}$ than students with lower skin phototype. A study involving 2895 multiethnic female respondents showed prevalence of $\mathrm{AV}$ in African American descents were 37\%, higher than the AV prevalence in Asian descent $(30 \%)$ and Caucasian $(24 \%){ }^{7}$ Similar to this study which the prevalence of AV was higher in skin phototype $\mathrm{V}$ ( $94.7 \%$ ), than in lower skin phototype (FST IV $78 \%$ and FST III 16.6\%). Richard et al. ${ }^{15}$ in a meta-analysis study found a significant difference $(95 \%$ CI $\mathrm{p}<0.05)$ of free testosterone level between white and black men. In black group the free testosterone level was $2.5-4.9 \%$ higher than white. Testosterone level as explained above has a crucial role in pathogenesis of AV especially in increasing sebum production and stimulating follicle keratinization. ${ }^{3}$

This study confirmed that skin phototype, gender, and stress level has significant effect on the incidence of AV among adolescents. Different with gender and skin phototype which is attached since birth, stress level is an external factor that happened in period of time. The effect of skin phototype and gender on the AV incidence will be felt long life and cannot be changed, but stress level can go higher and lower. Kholidah study among 48 college students in Yogyakarta showed significant result $(95 \%$ CI $p=0.001)$ that stress levels can be reduced by training of positive thinking. ${ }^{16}$

\section{Conclusions}

The conclusion from our study was that skin phototype, gender, and stress level have significant relationship in impacting AV among adolescents. Our analysis showed that gender is the most influential factor followed by skin phototype and stress level. We suggest in future research, respondents stress can be managed to lower level and the outcome of AV can be reevaluated to know further the effect of reducing stress with the clinical manifestation of AV.

\section{References}

1. James WD, Berger TG, Elston DM. Andrew's diseases of the skin. 11th ed. Philadelphia: Elsevier; 2016.

2. Brown RG, Harman K, Johnston G. Lecture notes: dermatology. 11th ed. West Sussex: Wiley Blackwell; 2017. pp 54-6.

3. Zaenglein AL, Graber EM, Thiboutot $\mathrm{DM}$, et al. Acne vulgaris and acneiform eruptions. In: Goldsmith LA, Katz SI, Gilchrest BA, et al. Fitzpatrick's dermatology in general medicine. 8th ed. New York: McGraw Hill; 2012. pp 897-915.

4. Shen Y, Wang TZ, Zhou C, et al. Prevalence of acne vulgaris in chinese adolescents and adults: a communitybased study of 17,345 subjects in six cities. Acta Derm Venereol 2012;92:404.

5. Noorbala MT, Mozaffary B, Noorbala M. Prevalence of acne and its impact on the quality of life in high school-aged adolescents in Yazd, Iran. J Pakistan Assoc Dermatol 2013;23:168-72.

6. Reddy KK, Lenzy YM. Racial considerations : skin of color. In: Goldsmith LA, Katz SI, Gilchrest BA, et al. Fitzpatrick's dermatology in general medicine. 8th ed. New York: McGraw Hill; 2012. pp 91-2.

7. Perkins AC, Cheng CE, Hillebrand GG, et al. Comparison of the epidemiology of acne vulgaris among Caucasian, Asian, Continental Indian and African American women. J Eur Acad Dermatol Venereol 2011;25:1054-60.

8. Bundy C, Cordingley L. Rook's textbook of dermatology. 9th ed. West Sussex: Wiley Blackwell; 2016. pp 11.1-11.2.

9. Ab-Hadi H, Awadh A. Study of psychological stress and acne vulgaris among pharmacy students. Value Heal J 2015;18:A170-180.

10. Rocken M, Schaller M, Sattler E, et al. Color atlas of dermatology. New York: Thieme; 2012.

11. Barrett K, Barman S, Boitano S, et al. Ganong's review of medical physiology. 25th ed. New York: McGraw-Hill; 2016. pp 1-32.

12. Cohen S, Kamarck T, Mermelstein R. A global measure of perceived Stress. 
Journal of Health and social behavior 1983;24:385-96.

13. Magin P, Pond D, Smith W, et al. Reliability of skin-type self-assessment: Agreement of adolescents' repeated Fitzpatrick skin phototype classification ratings during a cohort study. J Eur
Acad Dermatol Venereol 2012;26:1396-9.

14. Sadock BJ, Sadock VA, Ruiz P. Comprehensive textbook of psychiatry. 10th ed. London: Wolters Kluwer; 2017.

15. Richard A, Rohrmann S, Zhang L, et al.
Racial variation in sex steroid hormone concentration in black and white men: a meta-analysis. Andrology 2014;2:42835 .

16. Kholidah EN. Berpikir Positif untuk Menurunkan Stres Psikologis. J Psikol 2012;39:67-75 